\title{
Assessment of medium parameters in a closed space for a Hyperloop transport capsule with reference to reducing the energy demand of a transport system
}

\author{
Marcin Nowacki $^{1 *}$, Damian Olejniczak ${ }^{1}$, and Jarosław Markowski ${ }^{1}$ \\ ${ }^{1}$ Poznan University of Technology, Faculty of Transport Engineering, Piotrowo 3, 60-965 Poznan
}

\begin{abstract}
The increasing transport needs of societies are prompting manufacturers and inventors to seek new ways to satisfy them which are closely related to the development of new transport systems and means of transport. The current level of technological and social systems imposes limits on the implementation of new concepts which combine the advantages of existing systems currently functioning as separate entities. Combining the advantages of rail transport with the characteristics of air transport gave rise to the concept of a new transport system called Hyperloop, whose main purpose is to create a transport network combining the advantages of air and rail transport with low operating costs. The project assumes a pipeline structure and a transport capsule that moves inside its channels. To obtain high-velocity capsules, it is assumed that the pressure in the pipeline will be reduced, which will reduce in turn the losses resulting from the resistance of the moving capsule. Most means of transport in current use involve motion in open space. The proposed Hyperloop system involves different problems concerning the movement of the capsule as a means of transport within the confined space of the pipeline. These problems require specific analysis of conditions inside the system which depend on the velocity and shape of the capsule. These issues can be addressed using currently available numerical tools. An attempt to assess the phenomena associated with the flow of the capsule, using an important factor found in the pipeline space, was undertaken in the analyses conducted here. The study involved determination of the force acting on the nose of the capsule, an important component of its resistance to movement. The results and analyses were used to evaluate the differences in energy demand between two compared structures. On the basis of these results, conclusions were drawn regarding the directions for further modifications of the shape of the capsule aimed at reducing the energy demand necessary for its propulsion.
\end{abstract}

\footnotetext{
*Corresponding author: marcin.ro.nowacki@doctorate.put.poznan.pl
} 


\section{Introduction}

The reduction of emissions of harmful compounds into the atmosphere is linked to a wide range of human activities [1-4], which in turn are closely connected to the reduction of energy consumption in all fields of industry and functional processes of society [1-4]. Particular attention is being paid to the reduction of carbon dioxide emissions in order to reduce the use of fossil fuels in the production of energy based on combustion processes [1, 3-5]. Issues related to the broadly defined campaign to reduce energy consumption and thus reduce $\mathrm{CO} 2$ emissions are present in all fields of industry, e.g. energy, production, agriculture, and automotive and transport [2, 6-17]. The existing energy demand generated by the development of society is partially covered by the use of renewable energy sources, but this is only one of the directions being taken. Another direction is the development of energyefficient equipment. A third direction involves the development of new devices and systems that fulfil existing functions while reducing their energy demand [1, 3-5]. New concepts of energy systems for the propulsion of means of transport and of transport systems are being developed. One example is the fast tube transport system called Hyperloop, which involves the transport of people and goods within a closed pipeline system, using transport capsules moving at high speed. Implementation of this concept is planned, using appropriate conditions occurring inside the tubular track along which the transport capsule is to be moved. It is assumed that the capsule will move in a low-density medium, which will reduce the resistance to its movement and to enable high speeds, translating into reductions in energy demand and operating costs [1,3-5]. The conditions for the movement of the capsule inside the pipeline are crucial in achieving the intended results. Performing numerical tests gives us the opportunity to visualise systematic phenomena and optimal system design from the ground up. Optimising the shape of the capsule has a direct impact on the system's energy consumption; thus the main criterion for the study is the influence of the shape of the capsule's nose on the formation of resistance.

\section{Research methodology}

The general assumptions of the Hyperloop concept show a tendency towards reduction of the resistance associated with the movement of the transport capsule. The pipeline concept is designed to reduce the pressure of this factor contained inside the track. Nevertheless, at the planned high speeds of the transport capsule, this factor accumulates in the area in front of the moving capsule. The gas compressibility effect is omitted, thus simplifying the analysis. The article mainly shows values and distribution of pressure, aimed at illustrating constraints in effect during the movement of the capsule under certain conditions. Numerical investigations were conducted in simulated capsule movement conditions to evaluate the occurrence of increased pressure and its effects on the capsule. On the basis of these studies, the effect of the shape of the capsule's nose moving in the closed space of the pipeline was investigated. The tests, consisting of simulations of the motion of two capsule models with different frontal surfaces inside the pipeline, were carried out for the classical shape of the capsule's nose (Fig. 1a) and for a conceptual shape characterised by surfaces guiding the factor in front of the capsule into a longitudinal channel (Fig. 1b).

The tests were performed for the following boundary conditions: velocity $\mathrm{v}_{\text {cap }} 70,140$, 200 , and $340 \mathrm{~m} / \mathrm{s}$, with an air inlet in front of the nose and two pressure values inside the pipeline, i.e. $\mathrm{p}_{\mathrm{fc}}=10,130 \mathrm{~Pa}$ and $\mathrm{p}_{\mathrm{fc}}=101,300 \mathrm{~Pa}$. The computational domain presented in Fig. 1a, b is cuboid outside the pipeline, with the following dimensions:

$\begin{array}{ll}\text { X min: } & -5.298 \mathrm{~m} \\ \text { X max: } & -0.488 \mathrm{~m} \\ \text { Y min: } & -2.333 \mathrm{~m}\end{array}$




\section{Y max: $\quad 2.476 \mathrm{~m}$ \\ $\mathrm{Z}$ min: $\quad 17.465 \mathrm{~m}$ \\ $\mathrm{Z}$ max: $\quad 52.535 \mathrm{~m}$}

The average value of the pressure on the nose of the model was calculated; on this basis, the force acting on the capsule was estimated. A key analytic approach was to isolate the component of forces acting in the direction of the longitudinal axis $\mathrm{Z}$ of the moving capsule. The frontal area of the first model was $13.85 \mathrm{~m}^{2}$; of the second, $13.22 \mathrm{~m}^{2}$. The ratio of the area of the nose to a cross section of the tunnel area was 0.91 for the first model, 0.87 for the second. This was a crucial parameter in defining the solution. Modelling and simulation studies were conducted using internal flow simulation, laminar and turbulent flow type, and a k-epsilon turbulence model, implemented in the SolidWorks Flow simulation tool.

a)

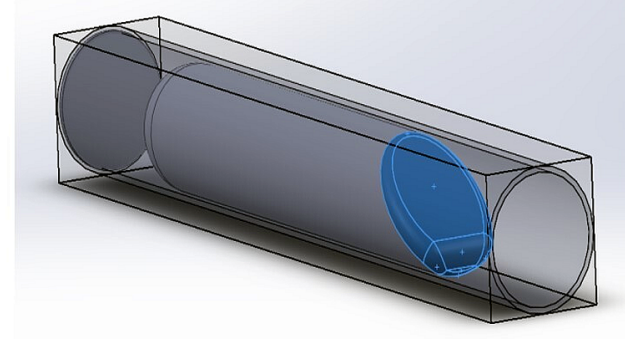

b)

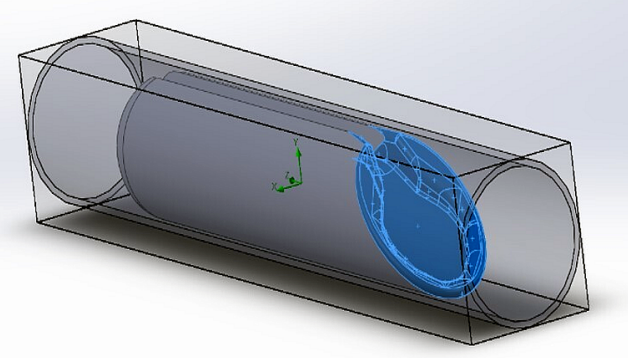

Fig. 1. Noses of analysed capsules:

a) conventional shape - capsule I; b) conceptual shape - capsule II

\section{Results}

Analysis of the results of numerical tests consisted of estimation of the cumulative pressure values of the factor in front of the capsule during its movement in the pipeline for assumed capsule velocity values and for the assumed values of the pressure of the factor in the pipeline system. The results of the analysed surface of the capsule's nose were calculated according to the accepted methodology; the pressure profiles on the nose for the four variants (Figs. 2-5) are presented to illustrate the results. These are images of the pressure distribution on the capsule's nose for the results obtained for the simulation of the following cases: capsule velocity $\mathrm{v}_{\text {cap }}=70 \mathrm{~m} / \mathrm{s}$, factor pressure in the tube space $\mathrm{p}_{\mathrm{fc}}=10,130 \mathrm{~Pa}$; capsule velocity $\mathrm{v}_{\mathrm{cap}}=70 \mathrm{~m} / \mathrm{s}$, factor pressure in the tube space $\mathrm{p}_{\mathrm{fc}}=101,300$ $\mathrm{Pa}$; capsule velocity $\mathrm{v}_{\text {cap }}=340 \mathrm{~m} / \mathrm{s}$; factor pressure in the tube space $\mathrm{p}_{\mathrm{fc}}=10,130 \mathrm{~Pa}$; capsule velocity $\mathrm{v}_{\text {cap }}=340 \mathrm{~m} / \mathrm{s}$; factor pressure in the pipe space $\mathrm{p}_{\mathrm{fc}}=101,300 \mathrm{~Pa}$.

The analysis consisted of determination of which of the models exhibited potentially greater energy efficiency due to lower resistance values. The value of the resistance force $F_{R}$ depends on the average value of the pressure acting on the nose of the capsule and is described by equation [3]:

where:

$$
F_{R}=C_{x} \cdot \rho \cdot A \cdot v_{c a p}^{2} \cdot g \quad[N]
$$

$C_{x}-$ drag coefficient,

$\rho$ - factor density in the pipeline $\left[\mathrm{kg} / \mathrm{m}^{3}\right]$,

$A$ - face surface area $\left[\mathrm{m}^{2}\right]$,

$v_{\text {cap }}-$ capsule velocity $[\mathrm{m} / \mathrm{s}]$,

$g-$ acceleration of gravity $\left[\mathrm{m} / \mathrm{s}^{2}\right]$. 
Knowing the individual values of the force of resistance, we can determine the value of the power required to overcome the resistance of the nose of the moving capsule. The resistance of the $P_{R}$ of the nose was determined according to equation [3]:

$$
P_{R}=\frac{F_{R} \cdot v_{c a p}}{2} \quad[\mathrm{~W}]
$$

To perform the calculations in accordance with the procedure described, it was necessary to determine the average pressure $p_{a v}$ acting on the nose of the capsule in the direction of the longitudinal axis of the capsule, the density of the factor in front of the capsule $\rho$, and the $C_{x}$ value for the analysed capsules. The values of the resistance force $F_{R}$ and the power generated by the $P_{R}$ for each of the analysed cases are determined and presented in Table 1 .
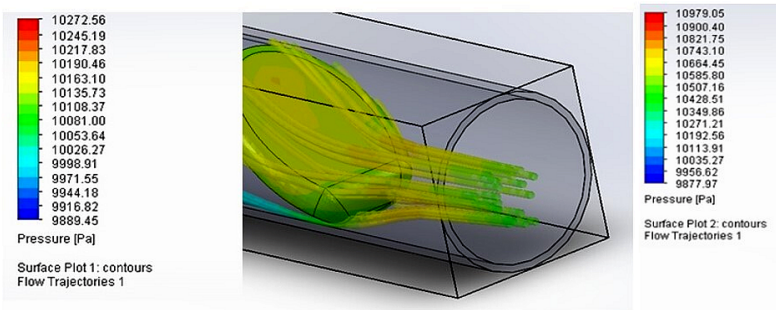

Fig. 2. Nose surface pressure distribution $(70 \mathrm{~m} / \mathrm{s}, 10,130 \mathrm{~Pa})$
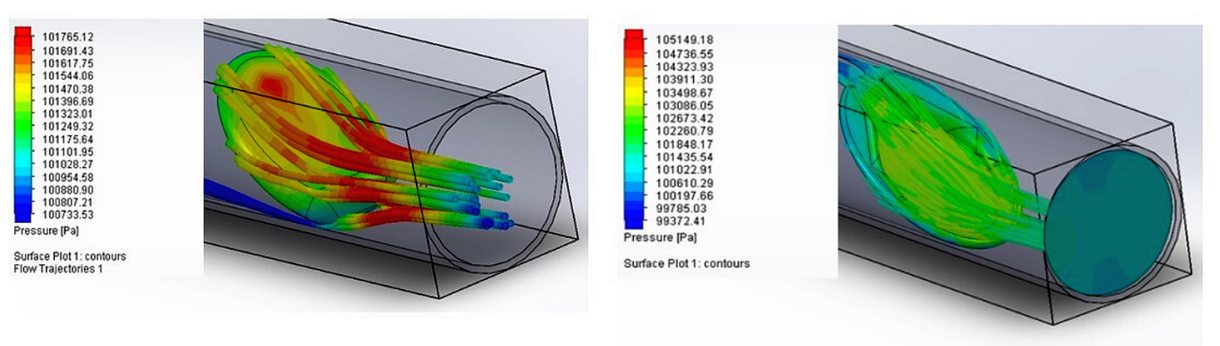

Fig. 3. Nose surface pressure distribution $(70 \mathrm{~m} / \mathrm{s}, 101,300 \mathrm{~Pa})$
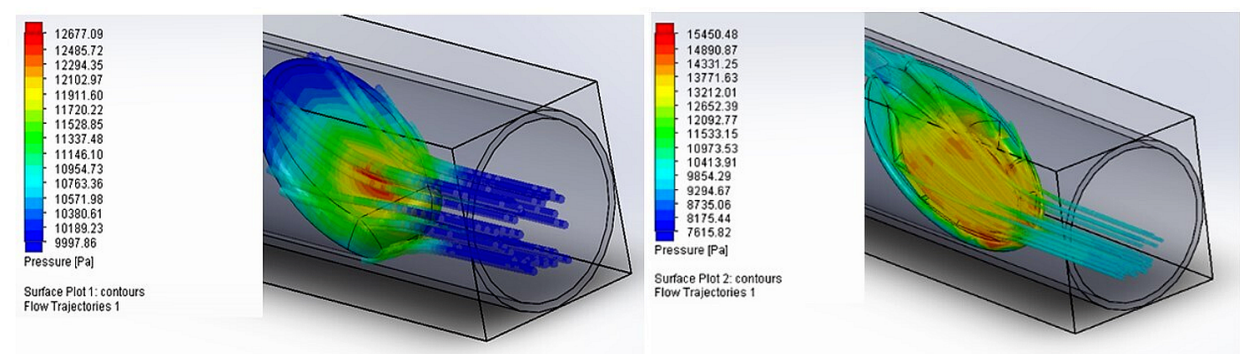

Fig. 4. Nose surface pressure distribution (340 m/s, 10,130 Pa)
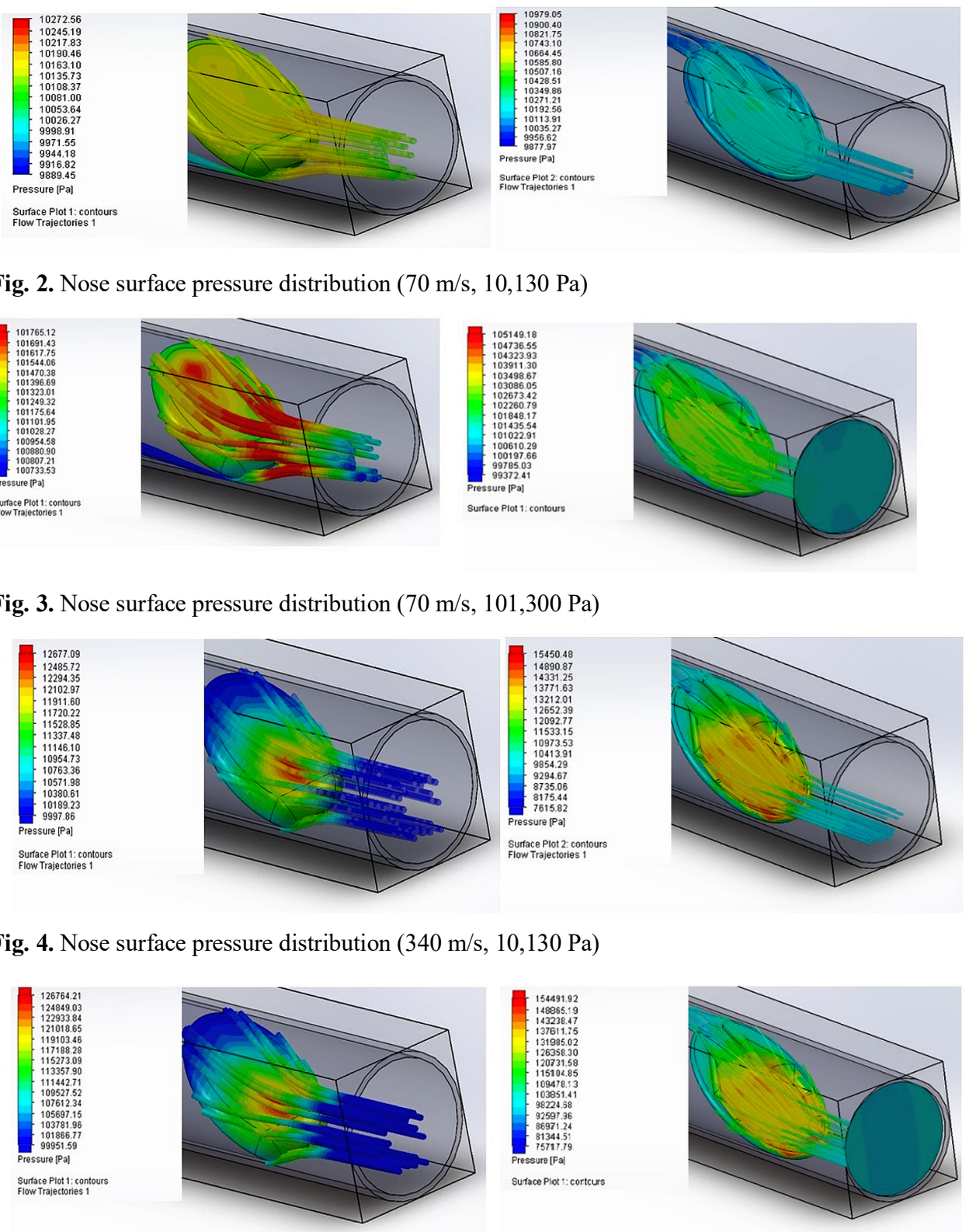

Flow Trajectories 1

Fig. 5. Nose surface pressure distribution $(340 \mathrm{~m} / \mathrm{s}, 101,300 \mathrm{~Pa})$ 
Table 1. Results of calculations for individual shapes of the capsule nose

\begin{tabular}{|c|c|c|c|c|c|}
\hline \multicolumn{6}{|c|}{ Capsule I } \\
\hline$p_{\mathrm{fc}}[\mathrm{Pa}]$ & & & 0,130 & & \\
\hline$p_{a v}[\mathrm{~Pa}]$ & $10,146.7$ & $10,264.2$ & 10,445 & $10,768.5$ & 11,168 \\
\hline$R[\mathrm{~J} /(\mathrm{kg} \cdot \mathrm{K})]$ & \multicolumn{5}{|c|}{287} \\
\hline$\rho\left[\mathrm{kg} / \mathrm{m}^{2}\right]$ & 0.12 & 0.12 & 0.12 & 0.13 & 0.13 \\
\hline$C_{x}[-]$ & \multicolumn{5}{|c|}{0.17} \\
\hline$v_{\text {cap }}[\mathrm{m} / \mathrm{s}]$ & 70 & 140 & 200 & 270 & 340 \\
\hline$F_{R}[\mathrm{kN}]$ & 14 & 56 & 114 & 207 & 328 \\
\hline$p_{\mathrm{fc}}[\mathrm{Pa}]$ & \multicolumn{5}{|c|}{101,300} \\
\hline$p_{a v}[\mathrm{~Pa}]$ & 101,462 & 102,640 & 104,446 & 107,674 & 111,660 \\
\hline$\rho\left[\mathrm{kg} / \mathrm{m}^{2}\right]$ & 1.21 & 1.22 & 1.24 & 1.28 & 1.33 \\
\hline$F_{R}[\mathrm{kN}]$ & 139 & 557 & 1136 & 2071 & 3284 \\
\hline \multicolumn{6}{|c|}{ Capsule II } \\
\hline$p_{\mathrm{fc}}[\mathrm{Pa}]$ & \multicolumn{5}{|c|}{10,130} \\
\hline$p_{a v}[\mathrm{~Pa}]$ & $10,209.6$ & $10,462.4$ & $10,824.1$ & $11,187.1$ & 11,454 \\
\hline$R[\mathrm{~J} /(\mathrm{kg} \cdot \mathrm{K})]$ & \multicolumn{5}{|c|}{287} \\
\hline$\rho\left[\mathrm{kg} / \mathrm{m}^{2}\right]$ & 0.12 & 0.12 & 0.13 & 0.13 & 0.14 \\
\hline$C_{x}[-]$ & \multicolumn{5}{|c|}{0.16} \\
\hline$v_{\text {cap }}[\mathrm{m} / \mathrm{s}]$ & 70 & 140 & 200 & 270 & 340 \\
\hline$F_{R}[\mathrm{kN}]$ & 13 & 53 & 108 & 196 & 311 \\
\hline$p_{\mathrm{fc}}[\mathrm{Pa}]$ & \multicolumn{5}{|c|}{101,300} \\
\hline$p_{a v}[\mathrm{~Pa}]$ & 102,098 & 104,632 & 108,256 & 101,901 & 114,397 \\
\hline$\rho\left[\mathrm{kg} / \mathrm{m}^{2}\right]$ & 1.21 & 1.24 & 1.29 & 1.21 & 1.36 \\
\hline$F_{R}[\mathrm{kN}]$ & 132 & 527 & 1076 & 1961 & 3110 \\
\hline
\end{tabular}

The next step was to compile and compare the resistance values $F_{R}$ of the noses of the capsules, based on the resistance values of the noses of capsules I and II at a pressure in the pipeline equal to $10,130 \mathrm{~Pa}$ and those of the noses of the same capsules at a pipeline pressure equal to 101,300 $\mathrm{Pa}$ (Fig. 6). In the two pressure simulations, the reduction in capsule II resistance was approximately $6 \%$ of the value of total capsule resistance.
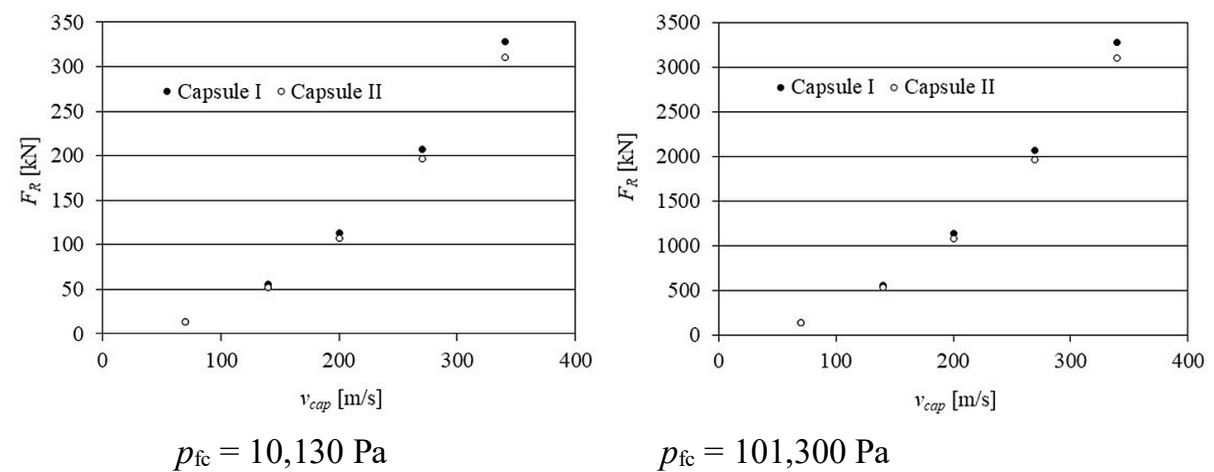

Fig. 6. Dependence of resistance on the velocity of the capsule at the simulated $\mathrm{p}_{\mathrm{fc}}$ value

In the next step, the resistance of the nose $P_{R}$ needed to overcome the resistance during capsule movement was determined. Calculations were made on the basis of equation (2); the results of the calculations are presented in Table 2. The values of frontal power obtained for the analysed capsules are shown in Fig. 7. Comparative analysis of the capsule nose 
resistance values for individual velocity values and simulated pipeline pressure values also resulted in a $6 \%$ difference in relative value. This is a consequence of the close physical relationship between the values of the force of resistance and of the power needed to overcome it.

Table 2. Values of force and resistance of the frontal capsule

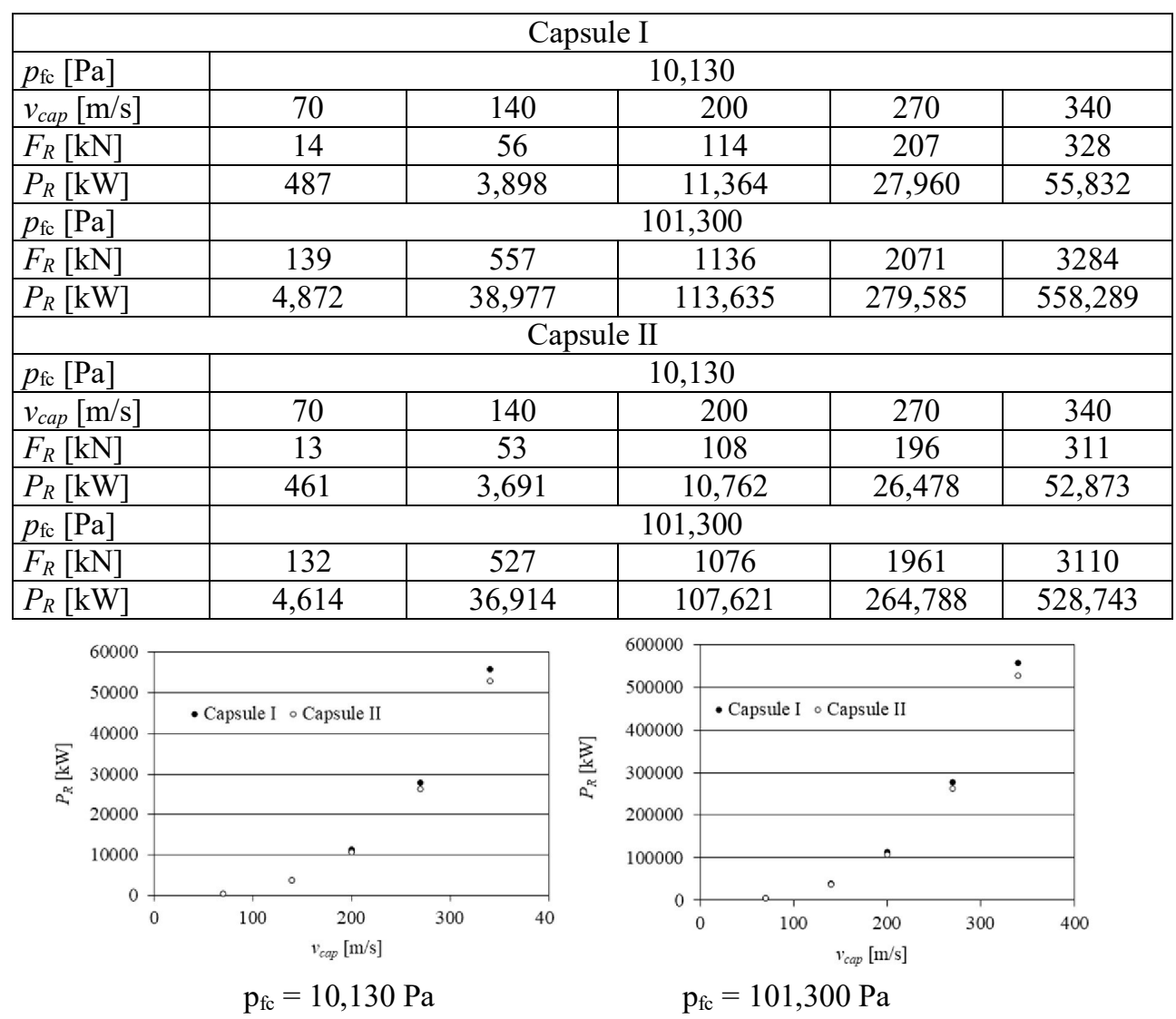

Fig. 7. Dependence of frontal resistance power on the velocity of a capsule with a simulated $p_{\mathrm{fc}}$ value

Studies conducted at the two values of the factor pressure in the pipeline space indicate the improved energy properties of the nose modelled for capsule II. The tests also show the close dependence of the generated and associated resistance to the pressure of the factor in the pipeline. Changing one row of factor values generates a change of one order of magnitude in the forces and resistances of the nose of the capsule. The analysis also shows that the increase in resistance between $140 \mathrm{~m} / \mathrm{s}$ and $200 \mathrm{~m} / \mathrm{s}$ is $7,466 \mathrm{~kW}$; between $200 \mathrm{~m} / \mathrm{s}$ and 270 $\mathrm{m} / \mathrm{s}, 16,596 \mathrm{~kW}$. Thus, the resistance force more than doubles. A similar situation applies to the comparison of speeds of 270 and $340 \mathrm{~m} / \mathrm{s}$. This demonstrates the need to select the optimum speed of movement of the capsule with reference to the energy requirements of the system.

\section{Conclusions}

Lowering the pressure inside the pipeline results in reduced (by one order of magnitude) resistance force values acting on the leading surfaces of the analysed capsules. This implies 
a similar dependence on the value of the resistance force acting on the nose and the resistance required to overcome this force at the specified velocity of capsule movement. The capsule with a conceptual nose will reduce energy requirements by around $6 \%$. This demonstrates the greater energy efficiency of the capsule model which incorporates an opening in the front of the structure. The increase in capsule velocity is related to the increase of the force and power of resistance of the front of the capsule and is described by the example equation $\mathrm{P}_{\mathrm{R}}=$ $0.8242 \cdot \mathrm{v}_{\text {cap }}{ }^{2}-147.34 \cdot \mathrm{v}_{\text {cap }}+7207.7$. It is necessary to carry out an analysis to determine the optimal value of the velocity of the capsules in the system in terms of energy.

\section{References}

1. J. Markowski, J. Pielecha, R. Jasiński, T. Kniaziewicz, P. Wirkowski, Development of alternative ship propulsion in terms of exhaust emissions, E3S Web of Conferences, 10 (2016)

2. J. F. D. Tapia, J. Y. Lee, R. E. H. Ooi, D. C. Y. Foo, R. R. Tan, Optimal $\mathrm{CO}_{2}$ allocation and scheduling in enhanced oil recovery (EOR) operations, Applied Energy, 184 (2016)

3. R. Warchol, J. Górski, Technologies of $\mathrm{CO} 2$ Emission Reduction in the Power Generation Cycles, Chemia i Inżynieria Ekologiczna, 10 (2003)

4. P. Wygonik, Engine and multitask airplane integration: criteria of engine parameters selection, Aircraft Engineering and Aerospace Technology, 85 (2013)

5. R. Zadrag. Supporting the Empirical Research on Diesel Engines with Multi-Equation Models, Advances in Mechatronic Systems, Mechanics And Materials, Book Series: Solid State Phenomena, 196 (2013)

6. R. Gryboś, Mechanika płynów, Skrypty Uczelniane, 1654, (Politechnika Śląska 1991)

7. J. Hunicz, An experimental study into the chemical effects of direct gasoline injection into retained residuals in a homogeneous charge compression ignition engine, International Journal of Engine Research, 17 (2016)

8. J. Hunicz, A. Medina, Experimental study on detailed emissions speciation of an HCCI engine equipped with a three-way catalytic converter, Energy, 117 (2016)

9. R. Jakubowski, Evaluation of performance properties of two combustor turbofan engine, Maintenance and Reliability, 17 (2015)

10. R. Jasinski, J. Markowski, J. Pielecha, Probe positioning for the exhaust emissions measurements, Procedia Engineering, 192 (2017)

11. B. P. Koirala, J. P. C. Avila, T. Gomez, R. A. Hakvoort,P. M. Herder, Local Alternative for Energy Supply: Performance Assessment of Integrated Community Energy Systems, Energies, 9 (2016)

12. J. Markowski, J. Pielecha, R. Jasinski, Model to assess the exhaust emissions from the engine of a small aircraft during flight, Procedia Engineering, 192 (2017)

13. I. Pielecha, Diagnostics of stratified charge combustion under the conditions of multiple gasoline direct injection, Journal of Thermal Analysis and Calorimetry, 118 (2014)

14. I. Pielecha, Modeling of gasoline fuel spray penetration in sidi engines, International Journal of Automotive Technology, 15 (2014)

15. I. Pielecha, W. Cieslik, Thermodynamic analysis of indexes of operation of the engine with direct fuel injection for idle speed and acceleration, Journal of Thermal Analysis And Calorimetry, 126 (2016)

16. J. Rudnicki, R. Zadrąg, Problems of Modelling Toxic Compounds Emitted by a Marine Internal Combustion Engine in Unsteady States (2014)

17. E. Sobiecka, T. Olejnik, Utilitarian Technological Solutions to Reduce CO2 Emission in the Aspect of Sustainable Development, Problemy Ekorozwoju, 12, (2017) 